\title{
FATIGUE-STRENGTH ANALYSIS IN THE VERY-HIGH-CYCLE REGIME OF THE TC17 TITANIUM ALLOY WITH MICRO SCRATCHES
}

\author{
VPLIV MIKRORAZ NA VISOKOCIKLIČNO TRAJNO NIHAJNO \\ TRDNOST TITANOVE ZLITINE TC17
}

\author{
Mingchao Ding1, Yuanliang Zhang ${ }^{1 *}$, Jinlong Wang1, Huitian $\mathbf{L u}^{2}$, \\ Hongwei Xian ${ }^{1}$, Ning $\mathrm{Hu}^{1}$, Zexin $\mathrm{Li}^{1}$ \\ ${ }^{1}$ School of Mechanical Engineering, Dalian University of Technology, Dalian, Liaoning 116023, China \\ ${ }^{2}$ College of Engineering, South Dakota State University, Brookings, South Dakota 57007, United States of America
}

Prejem rokopisa - received: 2019-05-27; sprejem za objavo - accepted for publication: 2019-12-23

doi: $10.17222 / \mathrm{mit} .2019 .114$

\begin{abstract}
The effect of surface defects, especially micro scratches, on the fatigue strength of the TC17 titanium alloy is studied in this paper. An ultrasonic fatigue experiment was conducted to obtain the geometric parameters of the surface scratches and the corresponding fatigue data. Fatigue failure of the specimens occurred from the scratches in this experiment. A new parameter $\sqrt{\text { area }_{\Delta}}$ is proposed to describe the fatigue damage caused by mechanical scratches; it is defined as the square root of the triangular area of a scratch section. A modified fatigue strength model of TC17 with a consideration of the mechanical scratches is established by applying the Murakami model and the term $\sqrt{\text { area }_{\Delta}}$. Compared with the reported models, the new model is demonstrated to be more suitable for the fatigue-strength prediction of TC17.

Keywords: TC17 titanium alloy, surface defects, micro mechanical scratches, scratch measurement, non-metallic inclusion, surface fatigue failure, fatigue strength

V članku avtorji opisujejo vpliv površinskih defektov, še posebej raz mikronske velikosti, na trajno nihajno trdnost titanove zlitine TC17. Izvedli so ultrazvočne preizkuse utrujanja materiala, da bi dobili geometrijske parametre površinskih raz in odgovarjajoče podatke o utrujanju materiala. Porušitev vzorcev zaradi utrujanja materiala je posledica raz na njihovi površini. Avtorji predlagajo nov parameter $\sqrt{\operatorname{area}_{\Delta}}$ za opis utrujenostnih poškodb zaradi mehanskih raz, ki je definiran kot kvadratni koren trikotnega preseka raze. Modificiran model za trajno trdnost titanove zlitine TC17 z upoštevanjem mehanskih raz, temelji na Murakamijevem modelu in izrazu $\sqrt{\operatorname{area}_{\Delta}}$. Primerjava z že prej predlaganimi (objavljenimi) modeli je pokazala, da je novi model primernejši za napoved trajne nihajne trdnosti Ti zlitine TC17.

Ključne besede: titanova zlitina TC17, površinski defekti, mikromehanske raze, merjenje velikosti raz, nekovinski vključki, poškodbe površine zaradi utrujanja, trajna nihajna trdnost
\end{abstract}

\section{INTRODUCTION}

Titanium alloys have been the workhorse materials of industrial fields such as the aerospace industry for many years. The TC17 titanium alloy possesses numerous great mechanical properties, such as high strength, low relative density and excellent high-temperature oxidation resistance. It is widely used in the manufacturing of core mechanical parts in aero-engines, such as advanced compressor blisk.

Even though the high surface quality of TC17 blisk is carefully controlled in engineering practice, the micro scratches still exist on the part's surface. These scratches are caused by the manufacturing or assembly process due to unintentional or wrong operation generally. The geometrical size of the micro scratch is small (the width is less than $50 \mu \mathrm{m}$ and the depth is less than $10 \mu \mathrm{m}$ ), these scratches have a significant impact on fatigue

*Corresponding author's e-mail:

zylgzh@dlut.edu.cn (Yuanliang Zhang) strength of the parts. ${ }^{1,2}$ Hence, there is a need to investigate the effect of micro mechanical scratches on the fatigue strength to have an empirical prediction model on TC17.

Many research results have been published on the study of the effect of surface condition, including micro mechanical scratches, on the fatigue property of metallic materials. If the scratch is regarded as a propagating crack, then fracture mechanics can be used to calculate the lifetime to failure. ${ }^{3}$ Fatigue-crack development from mechanically induced scratches is a small notch fatigue problem, where the stress concentrators are a few microns deep. ${ }^{4}$ The well-known term of $\sqrt{\text { area }}$ proposed by Murakami makes a great contribution to the study the effect of surface defects on fatigue strength. ${ }^{5} \mathrm{M}$. Filippini ${ }^{6}$ studied the fatigue sensitivity to small defects of a Gamma-titanium-aluminide alloy by an artificial defect of $\sqrt{\text { area }}=644 \mu \mathrm{m}$. The relevant parameters that govern the specific mechanisms of failure such as the range of stress-intensity factor, the threshold stress-inten- 
sity factor range are evaluated by employing the Murakami model. M. Åman ${ }^{7}$ carried out a bending fatigue test on notched specimens having different notch root radiuses and a small drilled hole at the notch root. The fatigue result shows that the $\sqrt{\text { area }}$ parameter model can be extensively applied to consider the effects of stress concentration, stress gradient and stress-intensity factors in combined linear and uniform loading. Y. Nishimura ${ }^{8}$ evaluated the sensitivity of fatigue strength to small scratches based on the $\sqrt{\text { area }}$ parameter model. As expected, the scratch depth exerts a significant effect on the fatigue limit.

Researchers have made an effort to modify the Murakami fatigue-strength model with the purpose of improving its applicability. M. Zhang ${ }^{9}$ assumed that the fatigue crack that initiated from the internal inclusion is a circumferential crack around a spherical cavity. Based on the assumption, Murakami's model was modified and its accuracy was checked by 28 groups of high-strength steels from the literature. The fatigue strength model with surface defects was modified by simplifying the surface defects as cracks using fracture mechanics. ${ }^{10}$ However, to the author's knowledge, little attention has been focused on the effect of actual mechanical scratches from machining defects on the fatigue performance for TC17.

It is worth noting that artificial defects with regular section shape are introduced in the above researches. The main reason for this method is that $\sqrt{\text { area }}$ can be obtained through simple section area calculation. However, the scratches from engineering practice are mainly caused by accidental operation. The formation of a mechanical scratch depends on the forces involved, the angle of the force, and the geometry of the object. ${ }^{11}$ Thus, the section shape of scratches from engineering practice cannot be regular. Moreover, the scratches are micron size in depth and width. So, artificial defects may not be suitable for the simulation of actual mechanical scratches from engineering practice.

Using standard surface-roughness parameters such as $R_{\mathrm{a}}$ and $R_{z}$ is one traditional type of characterizing the surface quality. Nevertheless, researchers have pointed out that it cannot be applied directly to express the fatigue-failure performance with these parameters. D. Arola ${ }^{12}$ pointed out that the average surface roughness does not account for the process-dependent profile valley radii, which has a critical influence on the stress-concentration factor. H. Javadi ${ }^{13}$ found that classic surfaceroughness parameters such as $\mathrm{Ra}$ are not the most efficient parameters to quantify the fatigue surface quality and the amplitude distribution parameter $M r 2$, which represents the valley material component, showed the highest direct correlation. J. C. Lacerda ${ }^{14}$ analyzed the evolution of the surface roughness of low-carbon steel. They found that the ratio between the inclination of the evolution curves of the peaks and valleys of the roughness could be one more indicator for predicting the failure of SAE 1020. It may be inadequate to express the fatigue damage caused by scratches using traditional surface-roughness parameters. So, it is obligatory to establish a new fatigue-damage parameter for micro mechanical scratches in order to set up an analytical connection between the fatigue strength and the scratches for TC17.

The main purpose of this study is to propose an improved analytical model of the fatigue strength for TC17 by redefining a new expression of $\sqrt{\text { area }}$ for micro mechanical scratches. An ultrasonic fatigue experiment was conducted to investigate the effect of mechanical scratches on the fatigue strength of TC17. Firstly, a physical scratch was predefined and quantitatively measured in the width and depth processed by ZYGOžs 3D optical profiler instrument beforehand. Then, an ultrasonic fatigue tensile experiment was carried out to obtain fatigue data, and fracture characteristics were observed with a Scanning Electron Microscope (SEM), along with the test experiments.

A new fatigue-damage parameter for mechanical scratches is defined as the square root of the triangular area of the scratch section, marked as $\sqrt{\text { area }_{\Delta}}$, combined with the classic Murakami theory. A modified fatiguestrength model for TC17 with the proposed parameter as the main variable is described. The accuracy of this model is proved by comparing with the results from the reported models in lectures. It can be concluded that it is more suitable to describe the characteristics of surface mechanical scratches using the proposed parameter. $\sqrt{\operatorname{area}_{\Delta}}$ provides a new approach to the study of the influence of the surface condition on fatigue performance.

\section{FATIGUE EXPERIMENT OF TC17}

\subsection{Material and specimen}

The mechanical properties of TC17 specimens in the experiment are listed in Table $\mathbf{1 .}$

The specimen used in the experiment is the hourglass type with a minimum diameter of $3 \mathrm{~mm}$, a radius curvature of the reduced section (notch radius) of 58.9 $\mathrm{mm}$, as shown in Figure 1. To remain the obvious scratches that can be measured, there were no fine

Table 1: Mechanical properties of TC17

\begin{tabular}{|c|c|c|c|c|c|}
\hline $\begin{array}{c}\text { Elastic modulus } \\
E(\mathrm{GPa})\end{array}$ & $\begin{array}{c}\text { Tensile strength } \\
R_{\mathrm{m}}(\mathrm{MPa})\end{array}$ & $\begin{array}{c}\text { Yield strength } \\
R_{\mathrm{p} 0.2}(\mathrm{MPa})\end{array}$ & $\begin{array}{c}\text { Vickers hardness } \\
\left(\mathrm{Kgf} / \mathrm{mm}^{2}\right)\end{array}$ & Total elongation & Reduction in area \\
\hline 111.5 & 1108.5 & 1060.5 & 356 & $15.8 \%$ & $42.0 \%$ \\
\hline
\end{tabular}




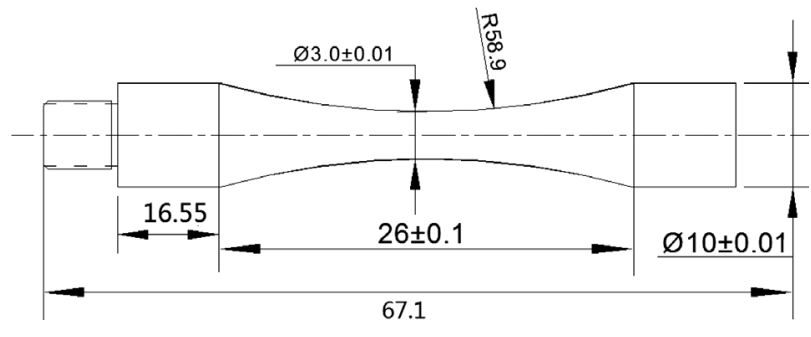

Figure 1: Specimen of TC17

grinding and polishing procedures in the final machining step.

\subsection{Ultrasonic fatigue experiment}

Ultrasonic fatigue experiments are widely used to investigate the fatigue property of TC17 because of its high efficiency and low energy consumption. ${ }^{15-17}$ In an ultrasonic fatigue test, appropriately designed specimens are stimulated to resonance vibrations at frequencies close to $20 \mathrm{kHz}$. The specially designed specimens, as shown in Figure 1, can meet the resonance requirement
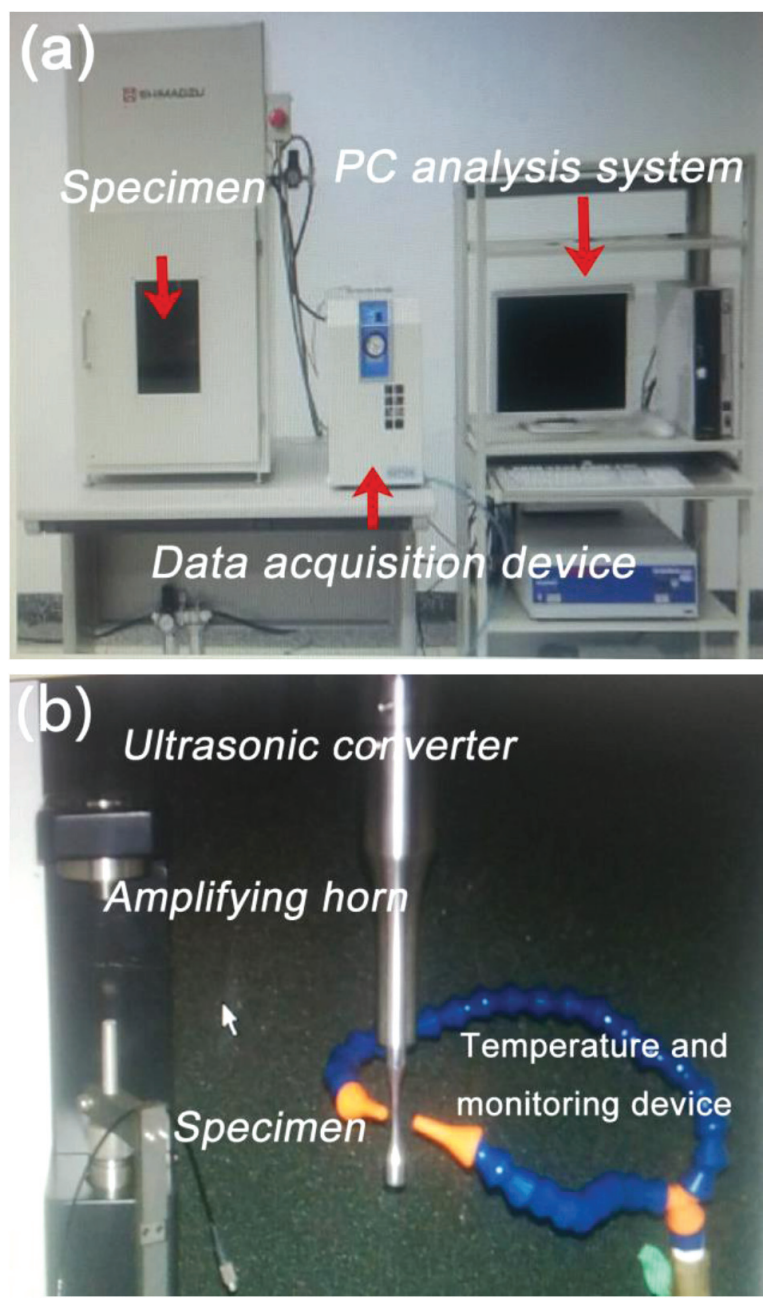

Figure 2: Ultrasonic fatigue experiment system: a) display of external equipment, b) loading specimen of $20 \mathrm{kHz}$ in the system. Vibrations are generated by a piezoelectric ultrasonic converter and are magnified with an amplifying horn. The fatigue test system is shown in Figure 2. Some studies indicate that the frequency effect is very small by using the ultrasonic testing machine. ${ }^{18-20}$

The fatigue experiment of TC17 in this study is carried out with an USF-2000 ultrasonic fatigue test system with a constant load ratio of $R=-1$ at room temperature $\left(20{ }^{\circ} \mathrm{C}\right)$. The practical situation of an aero-engine at high temperatures is not considered in this study. The test temperature can be monitored in real time by the temperature and monitoring device, as shown in Figure 2. A cooling system is adopted to keep the testing environment at room temperature. The characteristics of the fatigue-fracture morphology are observed by SEM. To obtain the stress amplitude when the specimens break, loading stress increases from initial stress amplitudes, $565 \mathrm{MPa}$, until fatigue failure occurs.

\subsection{Measurement of depth and width of scratches}

To study the effect of the mechanical scratches on fatigue strength of $\mathrm{TC} 17$, the parameters that can reflect the effective geometric characteristics of the scratches should be measured before the fatigue experiment.

The determination of the geometric parameters is supported by ZYGO's 3D optical profiler instrument for a better understanding of the mechanical scratches, as shown in Figure 3. ZYGO owns numerous advantages: high precise, non-contact surface measurement and nanoscale surface features. It consists of three core
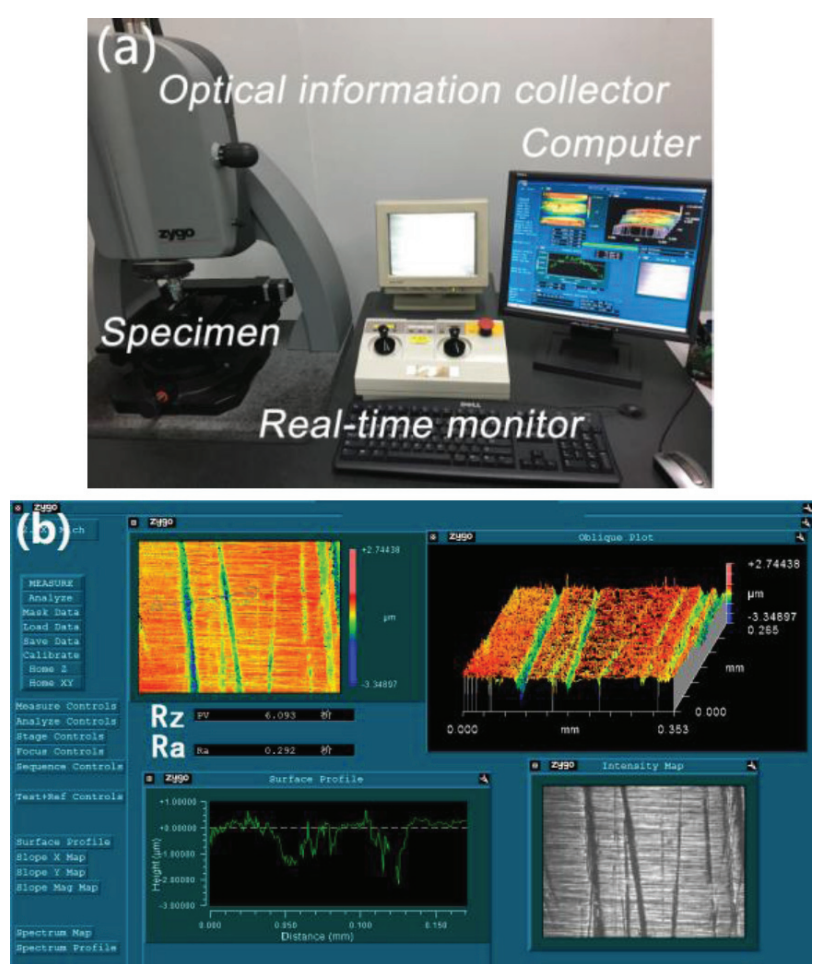

Figure 3: ZYGO 3D optical profiler instrument: a) equipment of ZYGO, b) operating system 
components: optical information collector, a real-time monitor to display the surface appearance of the specimen and a computer to process the geometric data.

Studies have reported that the angle and tip radius have exhibited an important influence on the fatigue property of the micro notched samples. ${ }^{12-21}$ The stress-concentration factor for a single surface notch is subjected to these parameters. However, when it comes to the actual micro mechanical scratch, there are many obstacles in measuring these parameters due to the irregular section shape and minimal geometric size, as shown in Figure 4.

It will be convenient to evaluate the fatigue damage using basic geometric parameters, such as the depth and width of the scratch. Three sections on one scratch are selected in Figure 4a and the schematic of the depth and width of section 1 are given in Figure $\mathbf{4 b}$. It can be seen in Figure 4 that the depth and width of each section can be clearly captured. Herein, $\bar{W}$ and $\bar{D}$ are defined as the width and depth of a whole scratch, which can be calculated as follows:

$$
\bar{W}=\frac{W_{1}+W_{2}+W_{3}}{3} ; \bar{D}=\frac{D_{1}+D_{2}+D_{3}}{3}
$$

Where $W_{1}, W_{2}$, and $W_{3}$ refer to the width of three sections and $D_{1}, D_{2}$, and $D_{3}$ refer to the depth of three sections in the scratch.

Since the width and depth of a whole scratch are defined, the next work is to measure the depth and width of the scratches. The specific measurement standards are as follows:
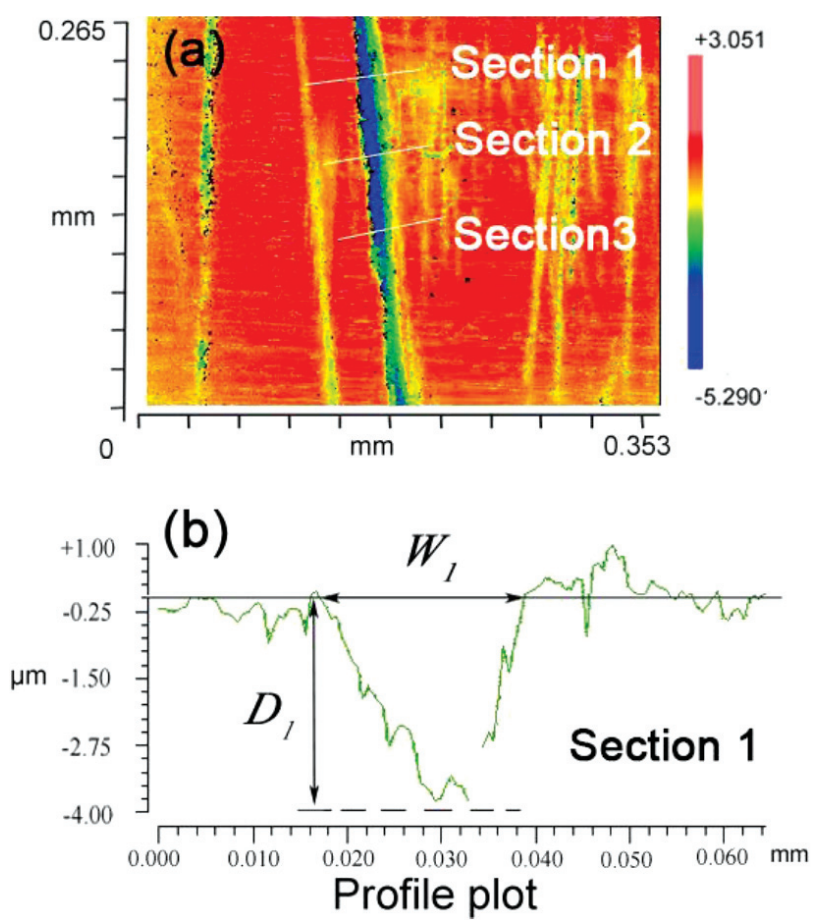

Figure 4: Profile plots of a scratch by ZYGO: a) three sections on one scratch, b) $W_{1}$ refers to the width of section 1 and $D_{1}$ refers to the depth of section 1 in one scratch
Stress concentration will happen in the minimum diameter area of the specimen due to the specially designed shape, as shown in Figure 1. Thus, the fatigue crack will choose and initiate from the scratches within the minimum diameter area of the specimen. So, the measurement area is selected at the minimum diameter of the specimen.

There can be many scratches among the measurement area. Due to the limit of the experimental capability, a maximum of three obvious scratches in the measurement area is collected instead of all the existing ones.

ZYGO is equipped with a real-time monitor, as shown in Figure 3a, which can display the appearance of the scratches during the measurement. The observation and selection for the obvious scratches can be achieved with the assistance of the monitor.

Once a scratch is located, the corresponding $R_{\mathrm{a}}$ and $R_{z}$ of the sample area and the depth and width of the scratch are determined at the same time.

For the locked scratch, three sections are selected at the positions with larger sizes of depth and width, instead of an equal distribution on the scratches Figure 4a.

Table 3 presents the measurement results of the depth and width of each scratch. Moreover, the average depth of scratches that will be used below is given in Table 2.

Table 2: Data of width and depth $(\mu \mathrm{m})$

\begin{tabular}{|c|c|c|c|c|c|c|c|}
\hline \multirow{2}{*}{$\begin{array}{l}\text { Speci- } \\
\text { men }\end{array}$} & \multicolumn{2}{|c|}{ Scratch 1} & \multicolumn{2}{|c|}{ Scratch 2} & \multicolumn{2}{|c|}{ Scratch 3} & \multirow{2}{*}{$\begin{array}{c}\text { Average } \\
\text { depth }\end{array}$} \\
\hline & $\bar{W}$ & $\bar{D}$ & $\bar{W}$ & $\bar{D}$ & $\bar{W}$ & $\bar{D}$ & \\
\hline 1 & 11.65 & 2.5 & 10.5 & 1.8 & & & 2.15 \\
\hline 2 & 6.70 & 1.91 & 14.43 & 1.58 & & & 1.75 \\
\hline 3 & 11.30 & 1.37 & 10.30 & 1.79 & 7.55 & 1.5 & 1.55 \\
\hline 4 & 12.30 & 1.49 & 15.07 & 0.93 & & & 1.21 \\
\hline 5 & 11.75 & 1.53 & 12.05 & 0.96 & 12 & 1.13 & 1.21 \\
\hline 6 & 6.70 & 1.91 & 14.43 & 1.58 & & & 1.75 \\
\hline 7 & 11.30 & 1.37 & 10.30 & 1.79 & 7.55 & 1.50 & 1.55 \\
\hline 8 & 12.73 & 1.57 & 13.50 & 1.76 & & & 1.67 \\
\hline 9 & 12.2 & 1.33 & & & & & 1.33 \\
\hline 10 & 9.80 & 1.35 & 11.60 & 1.52 & & & 1.44 \\
\hline
\end{tabular}

Surface roughness $R_{\mathrm{a}}$ and $R_{z}$ can be directly read in Figure 3b. Table 3 shows the corresponding average value of the surface roughness $R_{\mathrm{a}}$ and $R_{z}$ of the measurement areas. Surface-roughness parameters are measured beforehand in order to make a comparison of the fatigue-strength prediction below.

Table 3: Data of surface roughness $(\mu \mathrm{m})$

\begin{tabular}{|c|c|c|c|c|c|}
\hline Specimen & $R_{\mathrm{a}}$ & $R_{z}$ & Specimen & $R_{\mathrm{a}}$ & $R_{z}$ \\
\hline 1 & 0.340 & 4.94 & 6 & 0.297 & 7.98 \\
\hline 2 & 0.246 & 6.74 & 7 & 0.214 & 6.78 \\
\hline 3 & 0.180 & 5.47 & 8 & 0.285 & 7.25 \\
\hline 4 & 0.280 & 6.73 & 9 & 0.274 & 7.78 \\
\hline 5 & 0.298 & 6.78 & 10 & 0.246 & 6.87 \\
\hline
\end{tabular}




\section{FATIGUE EXPERIMENTAL DATA AND OBSERVATIONS}

Table 4 shows the results of the fatigue experiment. Fatigue failure begins to occur when the stress amplitude is above $615 \mathrm{MPa}$.

Table 4: Fatigue experiment data

\begin{tabular}{|c|c|c|c|c|c|}
\hline Specimen & $\begin{array}{c}\sigma_{\mathrm{a}} \\
(\mathrm{MPa})\end{array}$ & $\begin{array}{c}\text { Fracture } \\
\text { or not }\end{array}$ & Specimen & $\begin{array}{c}\sigma_{\mathrm{a}} \\
(\mathrm{MPa})\end{array}$ & $\begin{array}{c}\text { Fracture } \\
\text { or not }\end{array}$ \\
\hline 1 & 565 & No & 6 & 615 & No \\
\hline 2 & 600 & No & 7 & 620 & Yes \\
\hline 3 & 610 & No & 8 & 630 & Yes \\
\hline 4 & 615 & No & 9 & 645 & Yes \\
\hline 5 & 615 & No & 10 & 645 & Yes \\
\hline
\end{tabular}

Figure 5a shows a typical fracture characteristic, including crack initiation, propagation area including stable propagation and unstable propagation, and final momentary fracture area. The crack-initiation area presents neatly a narrow strip shape, as shown in Figure $\mathbf{5 b}$.
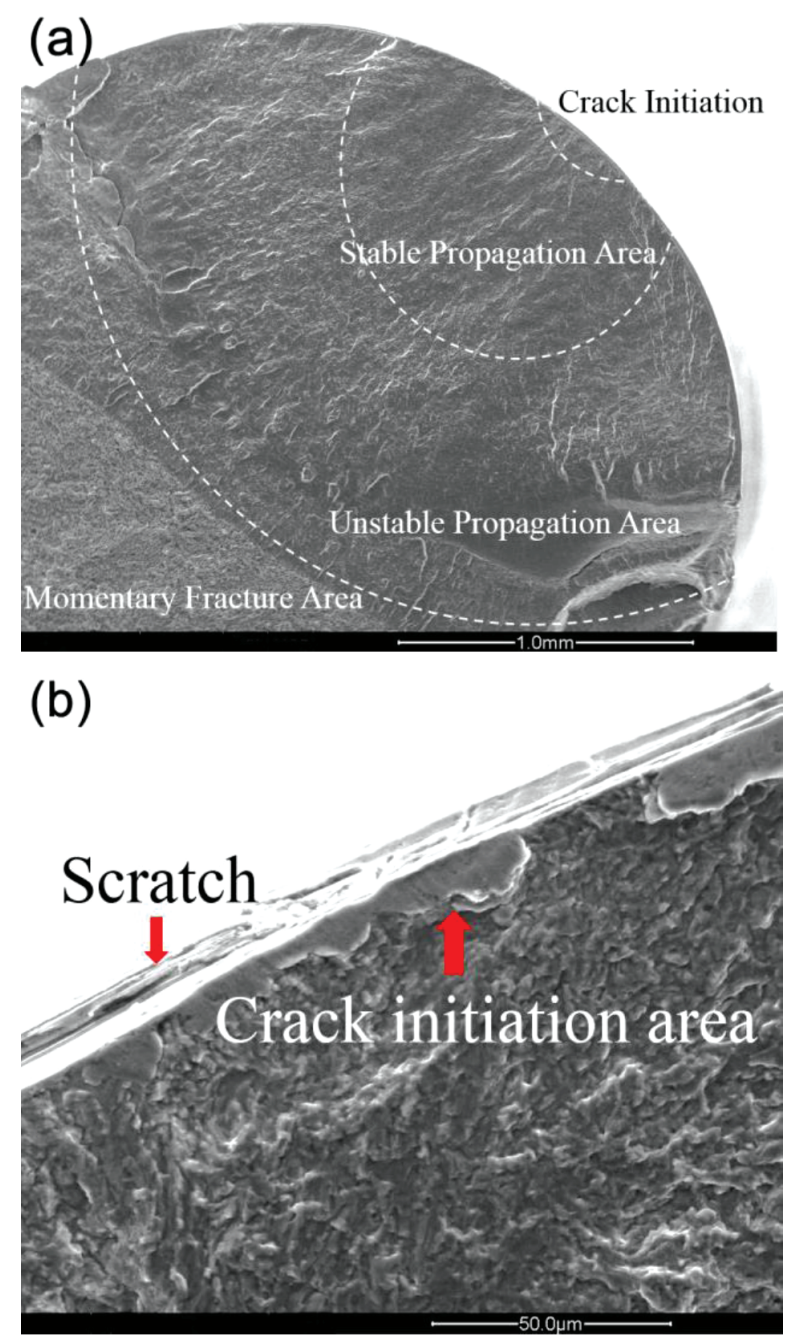

Figure 5: Surface topography of fatigue fracture: a) three parts in the overall morphology of fracture, b) crack initiated from the root of scratch
The fracture of the fatigue propagation is a river-shape pattern in this experiment.

Figure 5b shows the fatigue crack initiated from the root of the scratch. The slip mechanism that is induced by localized inhomogeneous slip deformation is the main reason for the surface failure. However, facets are not observed in the fracture, which can conclude that surface failure without facets is the fatigue failure mode in this study. ${ }^{22}$ A surface mechanical scratch can serve as stress concentrator and produce localized stress concentrations at the surface. The existence of surface scratches can be regarded as micro notches, which accelerated the formation of the initial crack. As a result, at these positions around the scratches where cyclic plastic deformation is higher than the average, which caused fatigue failure. ${ }^{23}$

As shown in Figures 5 and $\mathbf{6}$, there are no obvious inherent defects, fish-eyes or granular bright facets (GBFs) from the observation. However, the non-metallic inclusions are detected by EDX, which are seen as the black spots in Figure 6a. The analysis of a non-metallic inclusion is given in Figure 6b. The main elements of the non-metallic inclusions are carbon, oxygen, magnesium and calcium and a little titanium. Even though nonmetallic inclusions are scattered among sub-surface, fatigue failures still occur from the surface,
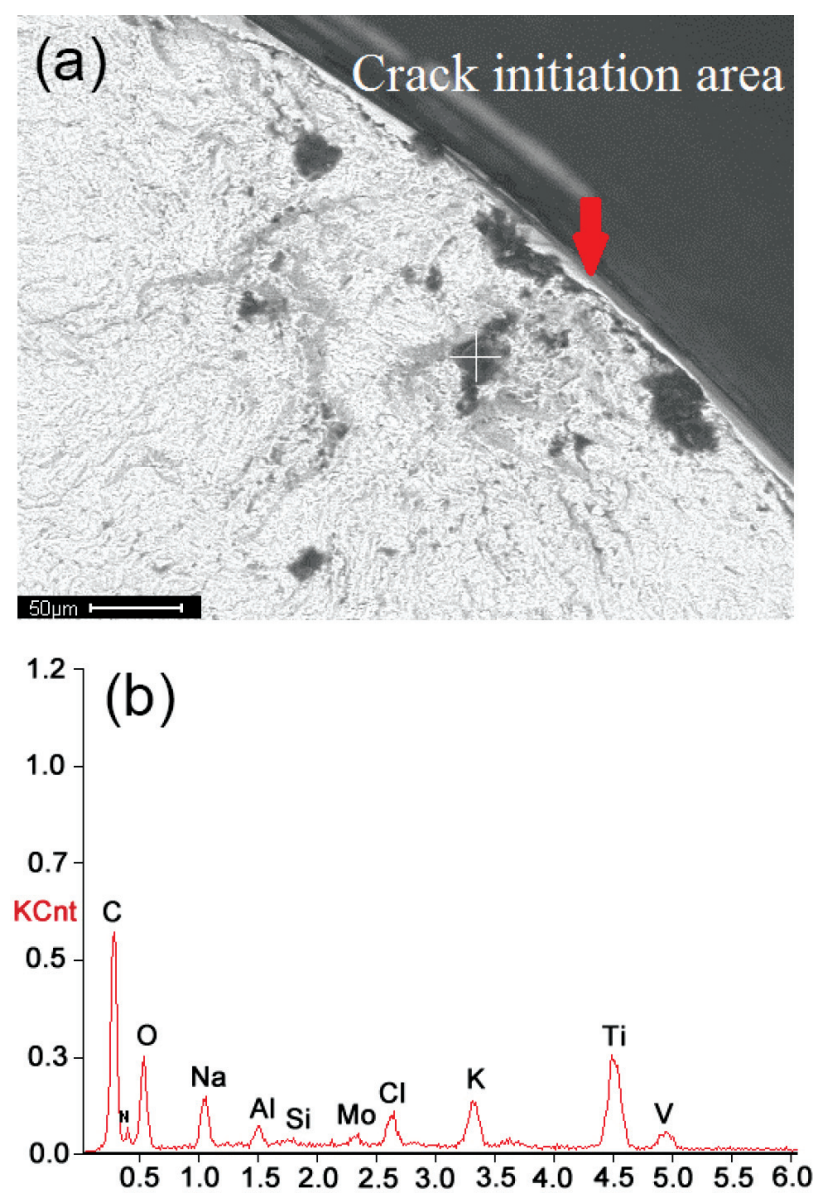

Figure 6: Nonmetallic inclusions of TC17: a) surface topography, b) main elements of non-metallic inclusion by EDX 
as shown in Figure 6a. As discussed above, it may be reasonable to suppose that non-metallic inclusions have no obvious effect on the fatigue-failure model of TC17 from this experiment.

\section{SURFACE FATIGUE STRENGTH MODELS OF TC17}

Murakami conducted intensive studies on the effect of surface defects on the fatigue behaviors of steel alloys. ${ }^{24-26}$ Y. Murakami et al. ${ }^{27}$ proved the Vickers hardness and $\sqrt{\text { area }}$, simple and useful method, for the prediction of the fatigue strength of materials containing small defects. $\sqrt{\text { area }}$ is defined as the square root of the area obtained by projecting a small defect or crack onto a plane perpendicular to the maximum principal stress.

First of all, the origination of $\sqrt{\text { area }}$ in Murakami's research should be clarified. It is to be noted that artificial defects on the specimens as shown in Figure 7 were pre-prepared by Murakami's team. ${ }^{27}$ Consequently, the projection area of surface defect can be calculated using simple area formulas. That is to say, $\sqrt{\text { area }}$ is a pure geometrical parameter ${ }^{28}$ and the initial size of a defect is the crucial geometrical parameter that controls the fatigue limit. ${ }^{29}$ Therefore, an appropriate shape to describe a section of the surface defect is the key step in the fatigue strength analysis.

\subsection{Current evaluations of surface fatigue strength}

The stress-intensity factor builds a bridge between the surface defect and the fatigue strength in fracturemechanics theory. It is well known that the threshold stress-intensity factor range, $\Delta K_{\text {th }}$, depends on the a crack size and decreases with a decreasing crack size ${ }^{30-32}$ For a surface crack, $K_{\text {Imax }}$ is given approximately as Equation (2), where $\sigma_{0}$ is the uniaxial tensile stress. ${ }^{33}$

$$
\Delta K_{\text {Imax }}=0.65 \times 2 \sigma_{0} \sqrt{\pi \sqrt{\text { area }}}
$$

(a)
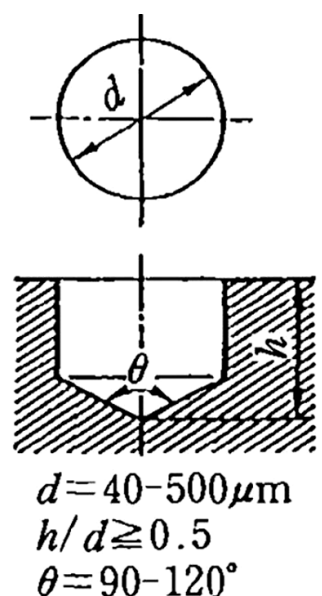

(b)

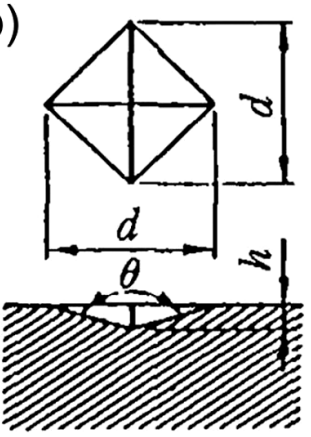

$d=71.5 \mu \mathrm{m}$
$\Delta K_{\mathrm{th}}$ is calculated by substituting the stress range at fatigue strength, $2 \sigma_{\mathrm{w}}$, for $\sigma_{0}$.

$$
\Delta K_{\mathrm{th}}=0.65 \times 2 \sigma_{\mathrm{w}} \sqrt{\pi \sqrt{\text { area }}}
$$

$\Delta K_{\mathrm{th}} \propto(\sqrt{\text { area }})^{1 / 3}$ is a significant finding to establish the fatigue-strength model in Murakamižs work. The well-known parameter model for the prediction of the fatigue strength is given below:

$$
\sigma_{\mathrm{w}}=\frac{c(H v+120)}{(\sqrt{\text { area }})^{1 / 3}}
$$

where $H v$ is the Vickers hardness, which is available from a material test, $c$ is a location parameter and $c=$ 1.43 for the surface defect.

In early research, there are two dominant methods to quantify fatigue damage in estimating the surface fatigue strength: using the actual depth of a crack and the surface roughness parameters.

For a single shallow circumferential crack, as shown in Figure 8a, Equation (5) is used to estimate the effective area, where ' $a$ ' is the depth of a very slender crack. $^{34}$

$$
\sqrt{\text { area }}=\sqrt{10} a
$$

M. Zhang ${ }^{35}$ substituted $R_{z}$ for ' $a$ ' in Equation (6), and the prediction value is much closer to the experimental value for FV520B.

$$
\sqrt{\text { area }}=\sqrt{10} R_{\mathrm{z}}
$$

Considering the effect of the surface roughness on the fatigue strength, especially for a periodic surface crack, as shown in Figure $\mathbf{8 b}$, a more accurate expression based on the accuracy of the depth and width of the notches is given in Equation (7), where ' $a$ ' is the average depth of the surface scratches and ' $2 b$ ' is the average peak distance. ${ }^{36}$ And Equation (8) shows a much more simplified expression for the surface defect. ${ }^{37}$

\section{(c)}

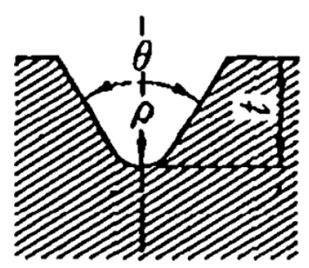

$$
\begin{aligned}
t & =5-300 \mu \mathrm{m} \\
\rho & =6-600 \mu \mathrm{m} \\
\theta & =60-70^{\circ}
\end{aligned}
$$

(d)

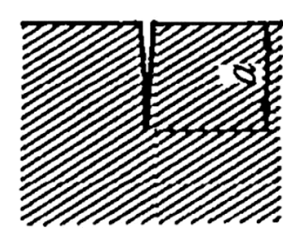

$a=30-260 \mu \mathrm{m}$

Figure 7: Geometries of artificial defects from Murakami's research: a) hole, b) Vickers indentation, c) notch, d) circumferential crack (redrawn from $^{29}$ ) 
(a)

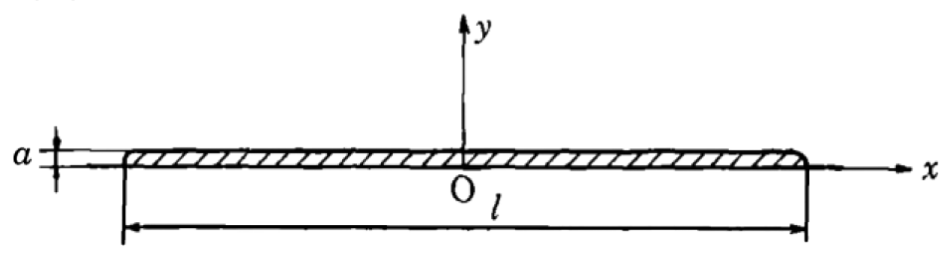

(b)

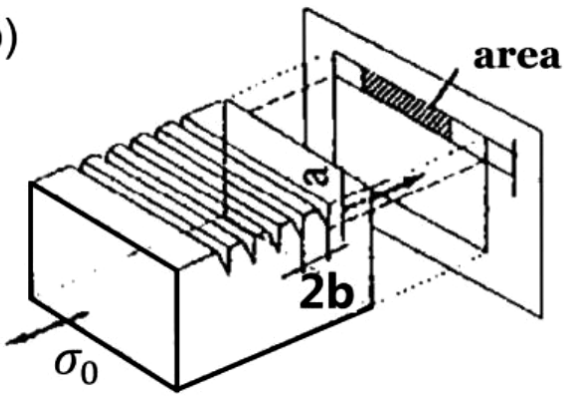

Figure 8: a) very shallow surface crack $(l>10 a)\left(\right.$ redrawn from $\left.^{35}\right)$, b) periodic surface crack (redrawn from ${ }^{36}$ )

Table 5: Fatigue-strength prediction results and errors for the reported models

\begin{tabular}{|c|c|c|c|c|c|c|c|c|}
\hline \multirow{2}{*}{$\sigma_{\mathrm{a}}(\mathrm{MPa})$} & \multicolumn{2}{|c|}{$\sqrt{\mathrm{area}}=2.97 R_{\mathrm{a}}$} & \multicolumn{2}{c|}{$\sqrt{\mathrm{area}}=\sqrt{10} R_{\mathrm{z}}$} & \multicolumn{2}{c|}{$\sqrt{\text { area }}=2.97 a$} & \multicolumn{2}{c|}{$\sqrt{\operatorname{area}}=\sqrt{10} a$} \\
\cline { 2 - 9 } & $\sigma_{\mathrm{w}}(\mathrm{MPa})$ & Error & $\sigma_{\mathrm{w}}(\mathrm{MPa})$ & Error & $\sigma_{\mathrm{w}}(\mathrm{MPa})$ & Error & $\sigma_{\mathrm{w}}(\mathrm{MPa})$ & Error \\
\hline 620 & 734 & $-18.6 \%$ & 408 & $34 \%$ & 527 & $15 \%$ & 522 & $16 \%$ \\
\hline 630 & 699 & $-11.4 \%$ & 403 & $37 \%$ & 521 & $17 \%$ & 516 & $19 \%$ \\
\hline 645 & 704 & $-9.7 \%$ & 399 & $40 \%$ & 541 & $16 \%$ & 535 & $18 \%$ \\
\hline 645 & 717 & $-11.7 \%$ & 407 & $39 \%$ & 534 & $18 \%$ & 529 & $19 \%$ \\
\hline
\end{tabular}

$$
\begin{aligned}
\frac{\sqrt{\text { area }_{\mathrm{R}}}}{2 b} & =2.97\left(\frac{a}{2 b}\right)-3.51\left(\frac{a}{2 b}\right)^{2}-9.74\left(\frac{a}{2 b}\right)^{3} \\
\text { for }\left(\frac{a}{2 b}\right) & <0.195 \\
\sqrt{\text { area }} & =2.97 a
\end{aligned}
$$

J. L. Wang ${ }^{39}$ brought the effect of surface roughness $R_{\mathrm{a}}$ in fatigue life modelling of FV520B-I:

$$
\sqrt{\text { area }}=2.97 R_{\mathrm{a}}
$$

Table 5 shows the prediction results of fatigue strength using the above four different expressions, Equations (5), (6), (8) and (9), where $\sigma_{\mathrm{a}}$ refers to experimental data and $\sigma_{\mathrm{w}}$ refers to the predicted value.
The required data for ' $a$ ' is from Table 2. The prediction error between experimental data and the predicted value is calculated:

$$
\text { Prediction Error }=\left[\frac{\sigma_{\mathrm{a}}-\sigma_{\mathrm{w}}}{\sigma_{\mathrm{a}}} \times 100\right] \%
$$

The predicted value is more than $10 \%$ larger than the experimental data when $\sqrt{\text { area }}=2.97 R a$ is applied to describe the surface defect, which would produce a potential danger in engineering practice. And more than $35 \%$ error is produced by $\sqrt{\text { area }}=\sqrt{10} R_{\mathrm{z}}$. When taking the depth of the scratch into consideration, a much lower prediction error, about $17 \%$, is generated by $\sqrt{\text { area }}=2.97 a$ and $\sqrt{\text { area }}=\sqrt{10} a$. (a)
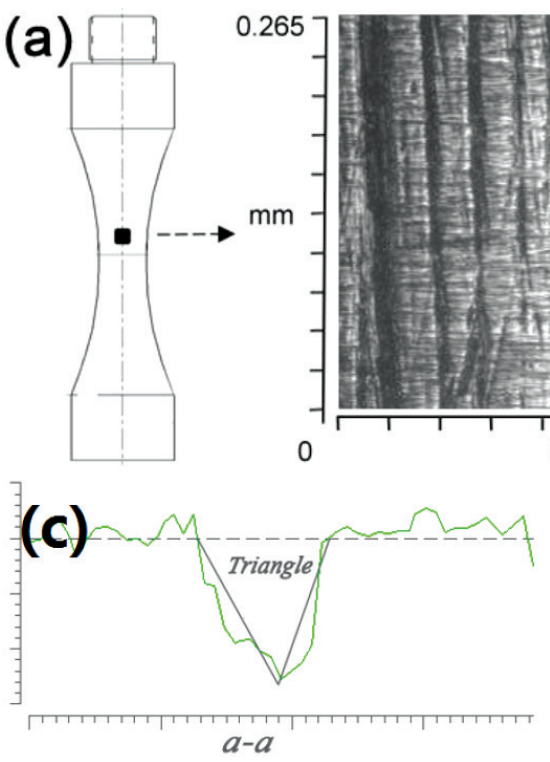
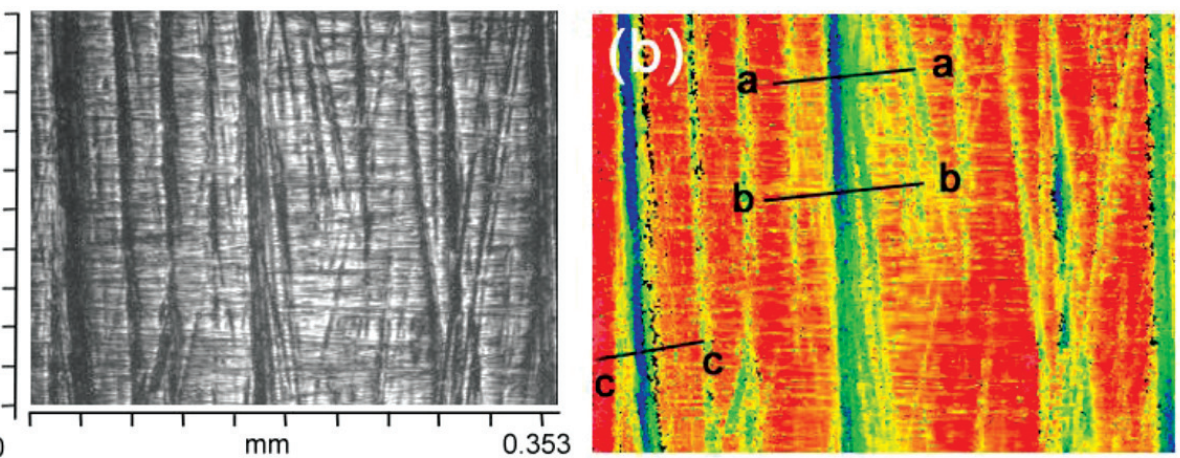

$+2.62372$

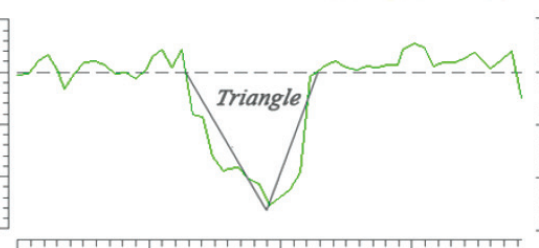

$b-b$

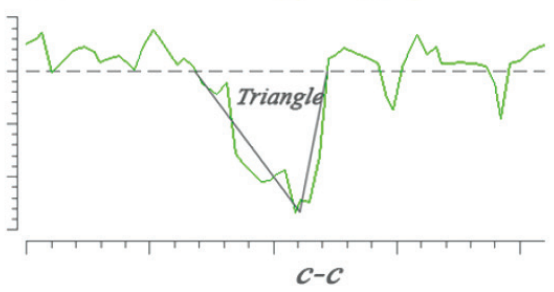

Figure 9: Triangle in mechanical scratch section: a) the appearance of scratch on intensity map, b) three sections on surface map, c) the profile plots of three section 
As discussed above, it may be inadequate to establish a link between the fatigue strength and the actual mechanical scratches in reported models for TC17. Therefore, a new way to describe the surface mechanical scratches is necessary for a fatigue-strength analysis of TC17 in this study.

\subsection{Surface fatigue-strength prediction based on $\sqrt{\text { area }_{\Delta}}$}

For parts that require a high surface quality, micro mechanical scratches from engineering practice are the main source of the surface defects instead of visible notches or holes. It can be conducted from the above discussion that the determination of the section shape of a scratch is the primary work in the fatigue strength analysis. Figure $\mathbf{1 0}$ shows the geometric morphology of micro scratches from engineering practice by ZYGO. As shown in Figures 9a and 9b, one scratch can be captured with a dark blue strip. Figure 9c shows the profile plot of three sections 'a-a', 'b-b', 'c-c' in one scratch. It can be inferred from the above observations that the approximate section shape for the scratch is a triangle.

Scratches of all specimens were observed according to the same method mentioned above to confirm the universality of a triangle for the section shape. Examinations of the surface map by ZYGO show that almost all the scratches have the same section shape, as observed in Figure 9c. Besides, all the specimens machined with the same process can also ensure the universality of a triangle for section shape. Apparently, in general and despite some dispersion, a triangle should be the closest approximate shape to describe the section of the scratch.

It is necessary to study the relationship between triangle area and the fatigue strength of TC17 based on Murakami theory. Thus, $\sqrt{\operatorname{area}_{\Delta}}$ is defined as the square root of the triangle area of scratch section for a quantitative characterization of the surface fatigue damage. It takes the triangle area of the scratches section as a crucial factor in the surface fatigue analysis, which can reflect the effect of depth and width on the fatigue strength for TC17.

The depth of the scratch is far smaller than the length. Consequently, the calculation of the stress-intensity factor does not take the length of the scratch into consideration. ${ }^{39,40}$

The square root of the triangle area of the scratch $i$ can be expressed as:

$$
\sqrt{\operatorname{area}_{\Delta i}}=\sqrt{\frac{\bar{W}_{l} \bar{D}_{l}}{2}}
$$

Where $\bar{W}_{1}$ is the width of the scratch $i$ and $\bar{D}_{1}$ is the depth of the scratch $i$, which can be calculated by Equation (1).

The micro crack always initiates from the maximum scratch due to the stress concentration. Therefore, fatigue damage caused by a micro scratch is determined by the maximum value $\sqrt{\operatorname{area}_{\Delta i}}$ :

$$
\sqrt{\operatorname{area}_{\Delta}}=\max \left\{\sqrt{\operatorname{area}_{\Delta i}}, i=1,2,3, \ldots, n\right\}
$$

Thus, a modified surface fatigue-strength model of TC17 applying the Murakami model and the new term of $\sqrt{\operatorname{area}_{\Delta}}$ is given:

$$
\sigma_{\mathrm{w} \Delta}=\frac{c(H v+120)}{\left(\sqrt{\operatorname{area}_{\Delta}}\right)^{1 / 6}}
$$

Table 6 shows the prediction results using the new model (13). The square root of the triangle area of every scratch is also listed in Table 6. Figure $\mathbf{1 0}$ shows the error comparison between the new model and the above four models.

Table 6: Fatigue strength prediction of TC17 based on $\sqrt{\text { area }_{\Delta}}$

\begin{tabular}{|c|c|c|c|c|c|c|}
\hline $\begin{array}{c}\sigma_{\mathrm{a}} \\
(\mathrm{MPa})\end{array}$ & $\begin{array}{c}\sqrt{\operatorname{area}_{\Delta 1}} \\
(\mu \mathrm{m})\end{array}$ & $\begin{array}{c}\sqrt{\operatorname{area}_{\Delta 2}} \\
(\mu \mathrm{m})\end{array}$ & $\begin{array}{c}\sqrt{\text { area }_{\Delta 3}} \\
(\mu \mathrm{m})\end{array}$ & $\sqrt{\text { area }_{\Delta}}$ & $\begin{array}{c}\sigma_{\mathrm{w} \Delta} \\
\text { MPa }\end{array}$ & Error \\
\hline 620 & 2.777 & 3.035 & 2.379 & 3.035 & 565.7 & $8.8 \%$ \\
\hline 630 & 3.157 & 3.449 & - & 3.449 & 553.8 & $12.1 \%$ \\
\hline 645 & 2.848 & - & - & 2.848 & 571.7 & $11.4 \%$ \\
\hline 645 & 2.575 & 2.965 & - & 2.965 & 567.9 & $12.0 \%$ \\
\hline
\end{tabular}

The maximum error is $12.1 \%$, and the minimum error is $8.8 \%$ when $\sqrt{\text { area }_{\Delta}}$ is used to predict the fatigue strength of TC17. Thus, compared with the reported four models, model (13) possesses an advantage with a $10 \%$ prediction error in the fatigue-strength prediction accuracy of TC17.

Fatigue failure always initiates from a local geometric discontinuity, such as holes, micro notches and scratches. This is because stress concentration will occur in these specific surface defects. In this study, it is observed that the micro mechanical scratches are the main surface defects for the specimens. Surface-rough-

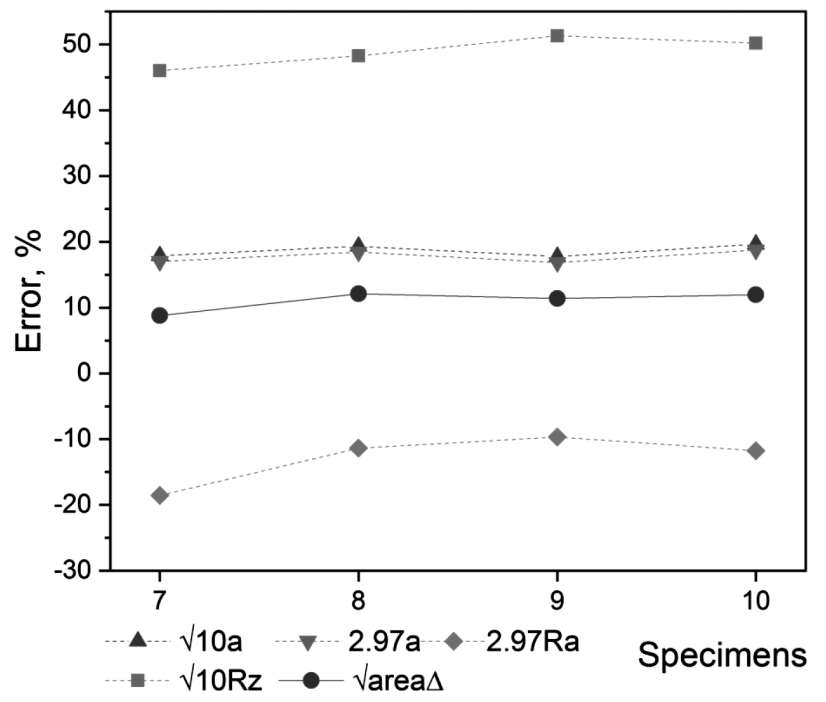

Figure 10: Error comparison between five models for TC17 
ness parameters can express the overall surface quality in a region of the measured area. However, the geometric characteristics of specific scratches that caused fatigue failure cannot be reflected by the surface roughness. The deficiency of the surface roughness in the fatiguestrength analysis is consistent with the current research results, as discussed in the introduction.

The depth of the scratch exerts a significant influence on the fatigue performance. ${ }^{8}$ Equations (5) and (8) can reflect the effect of the depth of the scratches on the fatigue strength and produce much lower prediction errors, around $17 \%$. So, it is reasonable and useful to analyze surface fatigue strength based on the geometric size of specific mechanical scratches. Once the width and depth of the scratches are reflected at the same time, the prediction results become much better. Therefore, it is reasonable to think of $\sqrt{\operatorname{area}_{\Delta}}$ as an effective and suitable parameter to describe the fatigue damage caused by mechanical scratches, which can be applied to a surface fatigue-strength prediction for TC17.

$\sqrt{\text { area }_{\Delta}}$ provides a novel approach to the study of the influence of the surface state on fatigue performance. Its applicability is validated by TC17 in this study, but it needs more validation experiments using other metals and forms of scratch. This paper establishes a framework on surface fatigue strength affected by micro mechanical scratches with laboratory experimental tests and data. As laboratories are expensive costs for both the test and the time, the sample size for the statistical empirical model may not be large enough for a comprehensive expression, but the primary practice and the results are promising, and could be the good examples of the research in this realm.

\section{CONCLUSIONS}

In this study, the width and depth of the scratches are measured by ZGYO to establish a new fatigue-damage parameter for the micro mechanical scratches; experimental data and observations are obtained from fatigue experiments to analyze the fatigue property of TC17. The main conclusions are summarized as follows:

- Failure model of fatigue crack initiation is revealed and named as the surface failure without facets. Crack initiation presents a neatly narrow strip shape. Although the non-metallic inclusions are observed, no experimental phenomenon or data indicate that the inclusions would affect the surface fatigue failure model in this study.

- The classic surface-roughness parameters such as $R_{\mathrm{a}}$ and $R_{z}$ have larger prediction error in the fatigue strength prediction from this experiment. This is because that roughness cannot reflect the geometric characteristics of specific mechanical scratches.

- A parameter by the term of $\sqrt{\operatorname{area}_{\Delta}}$ is proposed to describe the fatigue damage caused by mechanical scratches, which is defined as the square root of the triangle area of the micro scratch section.

- A fatigue strength model with the consideration of micro mechanical scratches of TC17 is established by the application of $\sqrt{\operatorname{area}_{\Delta}}$ based on Murakami theory. It is proved that the new model can be applied to a surface fatigue prediction of TC17 with a smaller error.

\section{Acknowledgment}

The authors gratefully acknowledge The National Natural Science Foundation of China (No. 51875082 \& No. 51375074). Also gratefully acknowledge the Fundamental Research Funds for the Central Universities (DUT17ZD230) and Key Research and Development Projects of Hui Ningxia Autonomous Region (2018BDE02045).

\section{REFERENCES}

${ }^{1}$ M. Nazmy, M. Staubli, G. Onofrio, Surface defect tolerance of a cast TiAl alloy in fatigue. Scripta. Mater., 45 (2001) 7, 787-792, doi:10.1016/S1359-6462(01)01097-1

${ }^{2}$ G. Léopold, Y. Nadot, T. Billaudeau, Influence of artificial and casting defects on fatigue strength of moulded components in Ti-6Al-4V alloy, Fatigue. Fract. Eng. M., 38 (2015) 9, 1026-1041, doi:10.1111/ffe. 12326

${ }^{3}$ J. B. Chang, Damage tolerance of metallic structures: analysis methods and applications. Philadelphia: ASTM special technical publication, 842, 1981

${ }^{4}$ A. Cini, P. E. Irving, Development of fatigue cracks from mechanically machined scratches on 2024-T351 aluminium alloy-part I: experimentation and fractographic analysis, Fatigue. Fract. Eng. M., 40 (2017) 5, 776-789, doi:10.1111/ffe.12544

${ }^{5}$ Y. Murakami, Metal fatigue: effects of small defects and nonmetallic inclusions, Oxford, Elsevier, 2002

${ }^{6}$ M. Filippini, S. Beretta, L. Patriarca, Fatigue sensitivity to small defects of a Gamma-Titanium-Aluminide Alloy, J.ASTM. Int., 9 (2012) 5, 1-12, doi:10.1520/JAI104293

${ }^{7}$ M. Åman, Y. Tanaka, Y. Murakami, Fatigue strength evaluation of small defect at stress concentration, Procedia Struct Integrity., 7 (2017), 351-358

${ }^{8}$ Y. Nishimura, K. Yanase, Y. Ikeda, Fatigue strength of spring steel with small scratches. Fatigue. Fract. Eng. M., 41 (2018) 7 , 1514-1528, doi:10.1111/ffe.12793

${ }^{9}$ M. Zhang, W. Q. Wang, P. F. Wang, Y. Liu, J. F. Li, The prediction for fatigue strength in very high cycle regime of high strength steel. Strenth, Fract. Comp., 9 (2015), 197-209, doi:10.3233/SFC-160191

${ }^{10}$ P. F. Wang, W. Q. Wang, M. Zhang, J. F. Li, Fatigue behavior and mechanism of KMN in a very high cycle regime. Mater. Test., 60 (2018) 1, 55-60, doi:10.3139/120.111117

${ }^{11}$ M. K. Khan, M. E. Fitzpatrick, S. V. Hainsworth, Effect of tool profile and fatigue loading on the local hardness around scratches in clad and unclad aluminium alloy 2024, Mat. Sci. Eng. A., 527 (2009) 1-2, 297-304, doi:10.1016/j.msea.2009.07.035

${ }^{12}$ D. Arola, C. L. Williams, Estimating the fatigue stress concentration factor of machined surfaces, Int. J. Fatigue., 24 (2002) 9, 923-930, doi:10.1016/S0142-1123(02)00012-9

${ }^{13}$ H. Javadi, W. Jomaa, D. Texier, Surface roughness effects on the fatigue behavior of as-machined inconel718, Solid. State. Phenom., 258 (2016), 306-309, doi:10.4028/www.scientific.net/SSP.258.306 
${ }^{14}$ J. C. de Lacerda, G. D. Martins, V. T. Signoretti, Evolution of the surface roughness of a low carbon steel subjected to fatigue, Int. J. Fatigue. 102 (2017), 143-148, doi:10.1016/j.ijfatigue.2017.05.010

${ }^{15}$ S. B. Jiao, L. Cheng, Q. T. Li, Study on very-high-cycle-fatigue property of aero-engine blades based on subcomponent specimen, Key. En.g Mater., 664 (2015), 87-95, doi:10.4028/www.scientific.net/ KEM.664.87

${ }^{16}$ Z. Y. Huang, H. Q. Liu, C. Wang, Fatigue life dispersion and thermal dissipation investigations for titanium alloy TC17 in very high cycle regime, Fatigue. Fract. Eng. M., 38 (2015) 11, 1285-1293, doi: $10.1111 /$ ffe. 12335

${ }^{17}$ L. Cheng, C. Gao, J. S. Shen, Investigation of very high cycle fatigue behavior of tc17 alloy, Adv. Mater. Res., 295-297 (2011), 1311-1314, doi:10.4028/www.scientific.net/AMR.295-297.1311

${ }^{18}$ S. B. Jiao, C. Gao, L. Cheng, A very high-cycle fatigue test and fatigue properties of TC17 titanium alloy, J. Mater. Eng. Perform., 25 (2016) 3, 1085-1093, doi:10.1007/s11665-016-1930-x

${ }^{19} \mathrm{I}$. Marines, An understanding of very high cycle fatigue of metals, Int. J. Fatigue, 25 (2003) 9-11, 1101-1107, doi:10.1016/S01421123(03)00147-6

${ }^{20}$ Y. Furuya, S. Matsuoka, T. Abe, Giga cycle fatigue properties for high-strength low-alloy steel at $100 \mathrm{~Hz}, 600 \mathrm{~Hz}$, and $20 \mathrm{kHz}$, Scripta. Mater., 46 (2002) 2, 157-162

${ }^{21}$ A. Inchekel, J. E. Talia, Effect of scratches on the fatigue behavior of an al-li alloy, Fatigue. Fract. Eng. M., 17 (1994) 5, 501-507

${ }^{22}$ X. Liu, C. Sun, Y. Hong, Effects of stress ratio on high-cycle and very-high-cycle fatigue behavior of a Ti-6Al-4V alloy, Mater. Sci. Eng. A., 622 (2015), 228-235, doi:10.1016/j.msea.2014.09.115

${ }^{23}$ W. Li, N. Gao, H.Q. Zhao, Crack initiation and early growth behavior of TC4 titanium alloy under high cycle fatigue and very high cycle fatigue, J. Mater. Res., 33 (2018) 08, 935-945, doi:10.1557/jmr.2017.476

${ }^{24}$ Y. Murakami, Material defects as the basis of fatigue design. Int. J. Fatigue, 41 (2012), 2-10, doi:10.1016/j.ijfatigue.2011.12.001

${ }^{25}$ Y. Murakami, M. S. Ferdous, C. Makabe, Low cycle fatigue damage and critical crack length affecting loss of fracture ductility, Int. J. Fatigue, 82 (2016), 89-97, doi:10.1016/j.ijfatigue.2015.05.006

${ }^{26}$ H. Masuo, Y. Tanaka, S. Morokoshi, Effects of defects, surface roughness and HIP on fatigue strength of Ti-6Al-4V manufactured by additive manufacturing, Procedia. Struct. Integ., 7 (2017), 19-26, doi:10.1016/j.prostr.2017.11.055
${ }^{27}$ Y. Murakami, Metal fatigue: effects of small defects and nonmetallic inclusions, Oxford, Elsevier, 2002, 58-59

${ }^{28}$ G. Léopold, Y. Nadot, T. Billaudeau, Influence of artificial and casting defects on fatigue strength of moulded components in Ti-6Al-4V alloy, Fatigue. Fract. Eng. M., 38 (2015) 9, 1026-1041, doi:10.1111/ffe. 12326

${ }^{29} \mathrm{~K}$. Takahashi, Y Murakami, Quantitative evaluation of effect of surface roughness on fatigue strength, Eng. Aga.t Fatigue, 764 (1999), 693-703, doi:10.1299/kikaia.62.1124

${ }^{30}$ B. N. Leis, A. T. Hopper, J. Ahmad, Critical review of the fatigue growth of short cracks, Eng. Fract. Mech., 23 (1986) 5, 883-898, doi:10.1016/0013-7944(86)90099-8

${ }^{31}$ H. Kitagawa, S.Takahashi, Fracture mechanical approach to very small fatigue crack growth and to the threshold condition, Trans. Jpn. SOC. Mech. Eng. A., 45 (1979) 399, 1289-1303

${ }^{32}$ H. Kobayashi, H. Nakazawa, A stress criterion for fatigue crack propagation in metals, Roc. $1^{\text {st }}$ Int. Conf. Mech Behav, Mater. Kyoto., 11 (1972), 199-208

${ }^{33}$ Y. Murakami, Metal fatigue: effects of small defects and nonmetallic inclusions, Oxford, Elsevier, 2002, 17

${ }^{34}$ Y. Murakami, Metal fatigue: effects of small defects and nonmetallic inclusions, Oxford, Elsevier, 2002, 18-19

${ }^{35}$ M. Zhang, W. Q. Wang, P. F. Wang, Fatigue behavior and mechanism of FV520B-I welding seams in a very high cycle regime, Int. J. Fatigue, 87 (2016), 22-37, doi:10.1016/j.ijfatigue.2016.01.001

${ }^{36}$ Y. Murakami, Metal fatigue: effects of small defects and nonmetallic inclusions, Oxford, Elsevier, 2002, 316

${ }^{37}$ S. X. Li, W. Y. Qing, W. J. Hui, Very high cycle fatigue properties of high strength steel, Beijing, Metallyrgical Industry Press, 2010

${ }^{38}$ J. L. Wang, Y. L. Zhang, Q. C. Sun, Giga-fatigue life prediction of FV520B-I with surface roughness, Mater. Design, 89 (2016), 1028-1034, doi:10.1016/j.matdes.2015.10.104

${ }^{39}$ Y. Murakami, Stress intensity factors handbook, vol. II, Berlin, Pergamon Press, 1987, 822-826

${ }^{40}$ Y. Murakami, Stress intensity factors handbook, vol. III, Berlin, Pergamon Press, 1987, 576-579 